\title{
Optimal Choice of Enterprise's Production Strategy under Constraints of Carbon Quota
}

\author{
Xiping Zheng ${ }^{1}$, Qiang $\mathrm{Guo}^{2}$, Zenglu $\mathrm{Li}^{2}$, and Ting Zhang ${ }^{2}$ \\ ${ }^{1}$ College of Management Science, Chengdu University of Technology, \\ Si Chuan Cheng Du, China \\ ${ }^{2}$ School of Economics and Management, Southwest Jiaotong University, \\ Si Chuan Cheng Du, China
}

Received 17 February 2018

Accepted 26 June 2018

\begin{abstract}
After analyzing the enterprise's production strategy under the constraints of carbon quota, this paper proposes new mathematical models aiming for the optimal choice of enterprise's production strategy under the monopoly and competitive environments respectively. Combining the neural network optimization theory, then the methods of Nonlinear Programming and Nash Equilibrium in Static Games are used to solve the models to obtain the enterprise's equilibrium quantity, the optimal carbon emission, and the profit of unit product in the low carbon technology. The study found that: under a monopoly environment, enterprises choose technology innovation strategy; under a competitive environment, enterprises use carbon trading strategies whenever carbon trading prices are low or high; however, there is no pure strategy Nash equilibrium when carbon trading prices are in the middle, in this case enterprises prefer to use the production strategies different from the competitor.

Keywords: carbon quota; carbon trading; production strategy; neural network optimization theory; pure strategy equilibrium
\end{abstract}

\section{Introduction}

In the last few years, the contradiction between environmental protection and economic development has become increasingly prominent. To achieve the emission reduction targets promised by countries in the Kyoto Protocol, first, the European Union Emissions Trading Scheme was implemented on January 1, 2005 by the European Union and the Trading Scheme became the first more sophisticated carbon credit trading system with multiple economies participating. Second, China has established carbon trading markets in Beijing, Shanghai and Chengdu, and achieved good results. The mission of energy-saving and emission reduction has permeated all walks of life in the current society. For enterprises, it is necessary to ensure the normal operation and development, but also to coordinate with the sustainable and healthy development of society and economy. Therefore, reducing the carbon dioxide emissions in industrial production has become a long-term constraint indicator in the development of the national economy, and the development of low-carbon economy has become hot issues of world's governments, enterprises and academia widespread concern and research.

With the government's emphasis and strengthening on environmental governance and advocacy as well as the development of low-carbon economy, the enterprises not only should follow the national development and climate protection policies and regulations, and conform to the trends of low-carbon economy development, they are also expected to look for a low-carbon development path according to their own characteristics and business interests in order to balance their long-term and short-term interests, weight the various policy objectives, as well as seek a win-win. Chinese enterprises are in this dilemma whether to grasp the rapid

This is an open access article under the CC BY-NC license (http://creativecommons.org/licenses/by-nc/4.0/). 
economic growth opportunities or to carry out low-carbon transformation. Existing carbon emissions policies internationally include: carbon taxes (additional very little management costs), carbon cap, carbon cap and trade. For enterprises, the first two policies can only be met by adjusting the output or using new technologies to reduce carbon emissions. Carbon cap and trade allows between enterprises to freely buy and sell the right of carbon emissions(Gong, 2013; Perdan, 2011), which can be achieved by adjusting the output, using the new technologies and buying or selling the right of carbon emissions and so on(Lu,2014). This article will study that companies should adopt low-carbon technology to reduce carbon emissions per unit to meet the carbon constraints, or to purchase carbon emissions to meet production requirements based on the carbon cap.

The carbon tax policies have attracted much attention by the scholars in many developed countries and regions who had tried or started to implement the carbon tax policy in the last few years. The research aspects of those polices and the methods on how to use them quite diverse.

For the emission reduction effect of the carbon tax, the earliest dating back to Barker (1993), he used the energy - environment - economic model to assess the carbon (energy) tax on the impact of the British economy. Based on the carbon tax policy, Baranzini (2000) argued that the main negative impacts of carbon taxes can be compensated by designing the tax system and using the financial revenue. Kemfert and Welsch (2000) used the dynamic CGE model to analyze the problem of economic efficiency that has caused by the government carbon tax policy. Zhu (2010) found that the collection of carbon taxes can effectively reduce $\mathrm{CO}_{2}$ emissions. $\mathrm{Hu}$ (2011) argued that it is the optimal tax refund mechanism that carbon taxes are used to subsidy of enterprise's consumers, in terms of the impact on the economy and the effect of emission reduction.

In addition, based on the trading policy of carbon emission rights, the existing researches mainly involved those issues from industry development to the influence and optimization of the transaction mechanism on logistics network and inventory management, the supply chain management and coordination under the low carbon scenario, the influence factors of supply chain carbon emissions and so on.

In terms of costs of enterprise's emission reduction, Dobos (2007) and Eral (2010) argued that carbon trading can increase enterprises' inventories and costs. From the strategy point of view, Jira et al. (2011) put forward an idea of enterprise's emission reduction of the supply chain through the economic analysis of enterprises, and argued that through environmental management and sustainable management they can achieve emission reduction of the supply chain. Chaabane et al. (2012) used the method of mixed integer optimization to study the supply chain design. Liu (2016) calculated the cost of emission reduction between China's industrial sector by the directional distance function, based on the marginal abatement costs curves, built up the inter-industry carbon trading model, and discussed that the carbon trading market has influences on the inter-industry emission reduction costs and market transaction prices. Hou (2013) studied the production decision-making of two-oligopoly and the optimal decision-making of enterprise's carbon emissions under the different competition levels, so put forward the countermeasures of enterprise's emission reduction. Xie and Zhao (2013) studied the pricing of the single-cycle two-level supply chain and the decision-making of emission reduction.

From the supply chain point of view, Subramanian et al. (2007) analyzed the manufacturer's response strategy with three-stage game under the background of government-issued carbon emission restrictions or carbon trading system. Barari (2012) used the evolutionary approach to coordinate vertical cooperation in supply chain through contractual means, not only to reduce emissions, but also to improve the benefits. Wang et al. (2014) used the method of revenue-sharing contract to coordinate vertical cooperation on emission reduction in the supply chain. Wong et al. (2012) used the newsboy model to discuss the impact of carbon tax and carbon trading policies on operational decision-making. Huang et al. (2014) used the stochastic differential game model, in the context of duopoly electricity market, to study the use of benefit-sharing contract to coordinate vertical cooperation on emission reduction in the supply chain. Liu (2015) analyzed the problem of horizontal cooperation on emission reduction in a two-level supply chain consisting of a single supplier and multiple retailers. Considering the investment costs of carbon emissions reduction and the willingness to pay a high price for low-carbon products and the price effect of the products purchase quantity, 
Guo (2017) studied the cooperation strategy of carbon emissions reduction in supply chain system, based on the study of the total amount of carbon emissions - the regulation of excess transactions. Li (2016) focused on two-level supply chain consisting of a single retailer and a single supplier, established a carbon trading model including investment of emissions reductions, and discussed the situation of carbon trading between enterprises based on the upper and lower limits of corporate carbon quota.

Finally, our paper is related to the literature on the computational intelligence. In intelligent information processing, under the mode of low carbon economy, $\mathrm{Hu}$ et al. (2015) investigated the optimization decision problem of supplier selection in green procurement. Xie et al. (2012) gave a new definition of probability distribution function of random set theory. López-Yáñez et al. (2011) predicted time series of air pollution data taken in Mexico City and the Valley of Mexico using a novel intelligent associative mathematical model and an emergent coding technique. Georg and Roger (2009) discussed the further potential of rough set theory to support the management of information in workflow systems. Yu et al. (2011) introduced the fuzzy information entropy and fuzzy mutual information for computing relevance between numerical or fuzzy features and decision.

Throughout the above mentioned researches, among others, mainly focused on the impact of carbon tax policy on energy-saving and quantification function of costs of enterprise's carbon dioxide emissions, however, few scholars simultaneously considered the constraint of carbon quota enterprise's production strategy. In the context of carbon trading, this paper investigates the impact of carbon quota constraints on the choice of enterprise's production strategy. The government through the carbon quota policy guides enterprises to use low-carbon technology to produce products, so as to achieve the purpose of energy-saving and emission reduction, but the enterprises are fear of the costs of low-carbon technology. According to the previous study the cost function is often a concave function. On the one hand it is the pressure of carbon quota policy from the government, on the other hand enterprises face the dilemma that how to research and develop low carbon technology and how to put it in practices. Can carbon trading become a new choice of enterprises energy-saving production? When will the enterprises choose a carbon trading strategy?
What will the monopoly and the competitive market environment effects on production strategy of enterprises? The above questions are the motivations and the focuses to be addressed in this paper and we expect the research finding could provide a theoretical basis for enterprises to choose low-carbon technology.

The remainder of the paper is organized as follows. Section 2 provides brief scope and problem description. Section 3 introduces neural network optimization theory. Section 4 and 5 propose the models under the monopoly and competitive environment respectively along with how to solve these models using the nonlinear programming and Nash Equilibrium in Static Games methods. Section 6 provides some case study with description of the equilibrium analysis. The paper is concluded in Section 7.

\section{Scope and Problem Description}

This paper takes the production manufacturer as the research object. Assume that the total carbon emissions within the company's production cycle exceed the amount of carbon emissions allocated by the government, and the retail price of the product is only affected by the output. Under the constraint of carbon quotas, what production strategy should enterprises adopt: whether to purchase carbon emissions through carbon trading to meet production, or whether to update production technology to reduce carbon emissions per unit of product to meet the government's carbon quota. In the following, we will examine the selection of production strategies in the monopolistic and competitive markets, and use $t$ to refer to carbon trading and $s$ to refer to low-carbon technologies. The subsequent sections will give details about how to model and solve the above optimal choice problem under both environments.

\section{Neural Network Optimization Theory}

In this paper, nonlinear continuous feedback neural network is used to solve the enterprise production strategy optimization model, that is, a continuous feedback neural network with global exponentially stable equilibrium attractors is designed(Cao and Wang, 2004) and the enterprise production strategy optimization problem is mapped into a continuous feedback neural network. The nonlinear continuous feedback neural network steps are constructed as follows: 


$$
\left.\begin{array}{l}
C_{i} \frac{d u_{i}}{d t}=\sum_{j=1}^{n} T_{i j} v_{j}-\frac{u_{i}}{R_{i}}+I_{i} \\
v_{i}=g_{i}\left(u_{i}\right), i=1,2, \mathrm{~L}, n
\end{array}\right\}
$$

Where, $T=\left(T_{i j}\right)_{n \times n}$ is a continuous weighting matrix, $v_{i}=g_{i}\left(u_{i}\right)^{n \times n}\left(u_{i} \in R\right)$ is the nonlinear input and output function of the $i$ neuron, $C_{i}$ 、

$R_{i}$ and $I_{i}$ respectively represents the capacitance constant, resistance constant, and external current input constant of the $i$ neuron, $C_{i}>0, R_{i}>0$.

The matrix measure that defines $\mathrm{T}$ is:

$$
\mu(T)=\max _{1 \leq j \leq n}\left\lfloor T_{j j}+\sum_{\substack{i=1 \\ i \neq j}}^{n}\left|T_{i j}\right|\right.
$$

\section{Model under the Monopoly Environment}

In the monopoly market environment, there is only one enterprise, denote as Enterprise 1, which arranges the productions according to the total amount of carbon emissions $E$ allocated by the government. We assume that the production plan of Enterprise 1 is $q_{1}$, and in order to constrain the carbon emissions of the enterprise, the government requires the carbon quota not more than its planned total amount of carbon emissions, that is $E \leq q_{1} e$, where $e$ is the carbon emissions per unit of product of Enterprise 1. In order to complete the production plan, two production strategies are considered: 1) enterprises through carbon trading purchase carbon emissions targets; 2) enterprises improve production technology to reduce carbon emissions per unit of product. Retail prices of products are affected by their output, regardless of factors such as consumers' low-carbon awareness and corporate marketing efforts. According to the inverse demand function of the Cournot model (Xie, 2002; Jansen, 2017; Todd, 2016; Blanchet, 2015), the product retail price of Enterprise 1 is expressed as:

$$
p_{1}=a-b q_{1}
$$

Where $a, b>0$, The constant $a$ indicates the market potential demand, The parameter $b$ represents the price and demand sensitivity factor while $q_{1}$ measures the real output and $p_{1}$ is the market-clearing price.

\subsection{Carbon trading strategy $(t)$}

When Enterprise 1 chooses the carbon trading under the constraint of carbon emission to complete the production plan, the profit function of Enterprise 1 is formulated as below:

$$
\begin{aligned}
& \max _{q_{1}^{t}} \Pi_{1}^{t}=\left(a-b q_{1}^{t}\right) q_{1}^{t}+t\left(E-e q_{1}^{t}\right) \\
& \text { s.t. } \quad q_{1}^{t} \geq \frac{E}{e}
\end{aligned}
$$

where $t$ is the carbon trading price, it is exogenous variables determined by the carbon trading market and not affected by regional carbon supply relationships and financial fluctuations(Du, 2015). According to the nonlinear programming $(\mathrm{Hu}, 2007)$ and nonlinear continuous feedback neural network theory, the generalized Lagrangian multiplier $\lambda_{1}$ is introduced $(\mathrm{Hu}, 2007)$. The optimization problem of Eq. (4) can be written as:

$$
L_{1}=\left(a-b q_{1}^{t}\right) q_{1}^{t}+t\left(E-e q_{1}^{t}\right)+\lambda_{1}\left(e q_{1}^{t}-E\right)
$$

We assume that the K-T point is $q_{1}^{t *}$, so the K-T conditions of the problem are given as follows:

$$
\left\{\begin{array}{l}
-2 b q_{1}^{t *}-t e+a+\lambda_{1} e=0 \\
\lambda_{1}\left(e q_{1}^{t *}-E\right)=0 \\
\lambda_{1} \geq 0
\end{array}\right.
$$

Using Eq. (6) to solve the optimization problem in Eq. (5), several cases need to be considered:

$$
\begin{gathered}
\text { 1) If } \lambda_{1}>0 \text {, then } q_{1}^{t *}=\frac{E}{e} \text {; } \\
\lambda_{1}^{*}=\frac{2 E b+e(e t-a)}{e^{2}} \text {. If } t>\frac{a e-2 b E}{e^{2}} \text {, the }
\end{gathered}
$$

point is the K-T point, in this case, the optimal profit of Enterprise 1is:

$$
\Pi_{1}^{t^{*}}=\frac{(a e-E b) E}{e^{2}}
$$

2) If $\lambda_{1}=0$, then $q_{1}^{t *}=\frac{a-t e}{2 b}$. If $t \leq \frac{a}{e}$, the point is the K-T point, in this case the optimal profit of Enterprise 1is:

$$
\Pi_{1}^{t^{*}}=\frac{e^{2} t^{2}+2 t(2 E b-a e)+a^{2}}{4 b}
$$

Remark: when $0<t \leq \frac{a}{e}$, under the carbon trading strategy, the ${ }^{e}$ condition of the manufacturer to obtain the optimal profit is $\lambda_{1}=0, q_{1}^{t *}=\frac{a-t e}{2 b}$, and the enterprises can solve the profit ${ }^{2} b$ function to get the optimal output. The enterprises' production decision making is not affected by the carbon quota, and the enterprises can make the optimal production by purchasing the carbon targets.

\subsection{Technological innovation strategy}


Under the constraint of carbon emissions, enterprises through the innovation of production technology reduce carbon emissions per unit of product to meet the constraint of carbon quota. We assume that under the new technology of enterprise carbon emissions per unit of product is $e_{1}$, so the profit function of enterprise is:

$$
\begin{aligned}
& \max _{q_{1}^{s}, e_{1}^{s}} \Pi_{1}^{s}=\left(a-b q_{1}^{s}\right) q_{1}^{s}-\frac{k\left(e-e_{1}^{s}\right)^{2}}{2}+t\left(E-q_{1}^{s} e_{1}^{s}\right) \\
& \text { s.t. } \quad q_{1}^{s} \leq \frac{E}{e_{1}^{s}}
\end{aligned}
$$

Similarly, according to the nonlinear programming theory, the generalized Lagrangian multiplier is introduced. The optimization problem of Eq. (9) can be written as:

$$
L_{2}=\left(a-b q_{1}^{s}\right) q_{1}^{s}-\frac{k\left(e-e_{1}^{s}\right)^{2}}{2}+t\left(E-q_{1}^{s} e_{1}^{s}\right)+\lambda_{2}\left(E-q_{1}^{s} e_{1}^{s}\right)
$$

Let $\mathrm{K}-\mathrm{T}$ point be equal to $q_{1}^{*}, e_{1}^{*}$, then the K-T conditions of the problem are given as follows:

$$
\left\{\begin{array}{l}
-2 b q_{1}^{s *}-t e_{1}^{s}+a-\lambda_{2} e_{1}^{s}=0 \\
k\left(e-e_{1}^{s}\right)-t q_{1}^{s *}-\lambda_{2} q_{1}^{s *}=0 \\
\lambda_{2}\left(E-e_{1}^{s} q_{1}^{s *}\right)=0 \\
\lambda_{2} \geq 0
\end{array}\right.
$$

Using Eq. (11) to solve the optimization problem, several cases need to be considered:

1) When $\lambda_{2}>0$, there is no K-T point, no solution.

2) When $\lambda_{2}=0$, then

$q_{1}^{s *}=\frac{(a-t e) k}{2 b k-t^{2}}, e_{1}^{s *}=\frac{2 b e k-a t}{2 b k-t^{2}}$

When $t<\min \left(\frac{a}{e}, \sqrt{2 b k}, \frac{2 b e k}{a}\right)$, this point is

the $\mathrm{K}-\mathrm{T}$ point. In this case, the optimal profit of Enterprise 1 is:

$$
\Pi_{1}^{s *}=\frac{\left(e^{2} t^{2}+2 t(2 E b-a e)+a^{2}\right) k-2 E t^{3}}{2\left(2 b k-t^{2}\right)}
$$

When enterprises use low-carbon technology to produce, enterprises reduce carbon emissions per unit of product through low-carbon technology, according to the optimized production of profit function, enterprises will not be able to produce on the basis of the maximum output made by the government of the constraint of carbon quotas.

Proposition 1: Under the monopoly environment, if $0<t<\min \left(\frac{a}{e}, \sqrt{2 b k}, \frac{2 b e k}{a}\right)$, then the manufacturer is willing to use the technological innovation strategy.

Proof: Under the two production strategies, the manufacturer's optimal profit is:

$$
\Delta \Pi_{1}=\frac{\left(e^{2} t^{2}+2 t(2 E b-a e)+a^{2}\right) k-2 E t^{3}}{2\left(2 b k-t^{2}\right)}-\frac{e^{2} t^{2}+2 t(2 E b-a e)+a^{2}}{4 b}=\frac{t^{2}(a-e t)^{2}}{4\left(2 b k-t^{2}\right)}>0
$$

Proposition 1 shows that in the monopoly market, manufacturers are only willing to adopt low-carbon technology strategy, and gives up the carbon trading strategy. Because in the range of carbon trading prices, enterprises reduce carbon emissions per unit of product through low-carbon technologies not only to contribute to increase production under the constraint of carbon quota, but also to sell excess carbon targets. Compared to carbon trading strategies, technological innovation is more flexible, so in the monopoly environment the optimal production strategy of the enterprises is low-carbon technology.

\section{Model under the Competitive Environment}

Considering the two-oligopoly market composing of Enterprise 1 and Enterprise 2, two enterprises compete for the output and are all constrained by the carbon quota. So the inverse demand function of two enterprises can be written as:

$$
p=a-b\left(q_{1}+q_{2}\right)
$$

In the competitive environment, two enterprises can form four strategies combination: all adopt the carbon trading strategy; Enterprise 1 adopts carbon trading and Enterprise 2 uses low-carbon technology; Enterprise1 uses low-carbon technology and Enterprise 2 uses carbon trading strategy; all adopt low-carbon technology.

In the subsequent sections, we analyze the equilibrium quantity and profit of enterprises under the different production strategies.

\subsection{All adopt the carbon trading strategy}

When both enterprises all adopt carbon trading strategy, their profit functions can be written as:

$$
\begin{aligned}
& \Pi_{i}^{t t}=p q_{i}^{t t}+t\left(E-e q_{i}^{t t}\right) ; \\
& \text { s.t. } \quad E \leq e q_{i}^{t t}
\end{aligned}
$$

According to the nonlinear programming and the Nash equilibrium in static games method, the 
solutions can be provided based on the following cases:

1) If $\lambda_{1}=\lambda_{2}>0$, then $q_{1}^{t * *}=q_{2}^{t t *}=\frac{E}{e}$, and $\lambda_{1}=\lambda_{2}=\frac{e^{2} t+3 E b-a e}{e^{2}}$. The equilibrium profits of two enterprises can be written as:

$$
\Pi_{1}^{t * *}=\Pi_{2}^{t t *}=\frac{(a e-2 b E) E}{e^{2}}
$$

2) If $\lambda_{1}=\lambda_{2}=0$, then $q_{1}^{t t *}=q_{2}^{t t *}=\frac{a-e t}{3 b}$. The equilibrium profits of two enterprises can be written as:

$$
\Pi_{1}^{t * *}=\Pi_{2}^{t t *}=\frac{e^{2} t^{2}+9 E b t-2 a e t+a^{2}}{9 b}
$$

3) If $\lambda_{1}=0, \lambda_{2}>0$ then

$q_{1}^{t t *}=\frac{e^{2} t+E b-a e}{2 b e} ; q_{2}^{t t *}=\frac{E}{e}$ and $\lambda_{2}=\frac{e^{2} t+3 E b-a e}{2 e^{2}}$. The equilibrium profits of two enterprises can be written as:

$$
\begin{aligned}
& \Pi_{1}^{t *}=\frac{e^{4} t^{2}+\left(6 E b e^{2}-2 a e^{3}\right) t+E^{2} b^{2}-2 E a b e+a^{2} e^{2}}{4 b e^{2}} \\
& \Pi_{2}^{t *}=\frac{E\left(a e+t e^{2}-E b\right)}{2 e^{2}}
\end{aligned}
$$

Because of the symmetry of two enterprises, when $\lambda_{1}>0, \lambda_{2}=0$, one can refer to the above process, no more details are given here.

Proposition 2: When two enterprises adopt carbon trading strategy, if $\lambda_{1}=\lambda_{2}=0$, the profit is the optimal profit, and the following cases hold:

1) When $0<t<\frac{a e-3 E b}{e^{2}}, \lambda_{1}=\lambda_{2}=0$ is the optimal solution.

2) When $\frac{a e-3 E b}{e^{2}}<t<\frac{a e-E b}{e^{2}}$, then formula $\lambda_{1}=\lambda_{2}>0 \quad, \quad \lambda_{1}=\lambda_{2}=0$ hold, but the $\lambda_{1}=\lambda_{2}=0$ is the optimal value.

3) When $\frac{a e-E b}{e^{2}}<t \leq \frac{5 a e-3 E b}{5 e^{2}}$, then all the cases are true, we found that the enterprise's profit of is still the optimal solution when $\lambda_{1}=\lambda_{2}=0$.

4) When $\frac{5 a e-3 E b}{5 e^{2}}<t \leq \frac{a}{e}$, then all the cases are true, but there is no optimal profit, because Enterprise 1 has a preference for the output when $\lambda_{1}=0, \lambda_{2}>0$, while Enterprise 2 has a preference for the output when $\lambda_{1}=\lambda_{2}=0$.
5.2 Enterprise 1 uses carbon trading, while Enterprise 2 uses new technology

Enterprise 1 chooses the carbon trading strategy while enterprise 2 chooses to adopt the new technology, and the profit function can be written as:

$$
\begin{aligned}
& \left\{\begin{array}{l}
\Pi_{1}^{t s}=p q_{1}^{t s}+t\left(E-e q_{1}^{t s}\right) ; \\
\text { s.t. } \quad E \leq e q_{1}^{t s}
\end{array}\right. \\
& \left\{\begin{array}{l}
\Pi_{2}^{t s}=p q_{2}^{t s}-\frac{k\left(e-e_{2}^{t s}\right)^{2}}{2}+t\left(E-e_{2}^{t s} q_{2}^{t s}\right) ; \\
\text { s.t. } \quad E \geq e_{2}^{t s} q_{2}^{t s}
\end{array}\right.
\end{aligned}
$$

According to the Nash static game and nonlinear programming method, the following cases are considered:

1) If $\lambda_{1}=\lambda_{2}=0$, then $q_{1}^{t s *}=\frac{\left(b k-t^{2}\right)(a-e t)}{b\left(3 b k-2 t^{2}\right)} ; q_{2}^{t s *}=\frac{(a-e t) k}{3 b k-2 t^{2}} ; e_{2}^{t s *}=\frac{3 b k e-(a+e t) t}{3 b k-2 t^{2}}$ ;2) If $t \leq \min \left\{\frac{a}{e}, \sqrt{b k}, \frac{-a+\sqrt{12 b k e^{2}+a^{2}}}{2 e}\right\}$, then this solution is the $\mathrm{K}-\mathrm{T}$ point, and equilibrium profit functions of the two enterprises can be written as:

$\Pi_{1}^{s * *}=\frac{k^{2} b^{2}\left(e^{2} t^{2}+9 E b t-2 a e t+a^{2}\right)-2 b k t^{2}\left(e^{2} t^{2}+6 E b t-2 a e t+a^{2}\right)+t^{2}\left(e^{2} t^{2}+4 E b t-2 a e t+a^{2}\right)}{b\left(3 k b-2 t^{2}\right)^{2}}$ $\Pi_{2}^{s t}=\frac{2 b k^{2}\left(e^{2} t^{2}+9 E b t-2 a e t+a^{2}\right)-k t^{2}\left(e^{2} t^{2}+24 E b t-2 a e t+a^{2}\right)+8 E t^{5}}{2\left(3 k b-2 t^{2}\right)^{2}}$

3) If $\lambda_{1}>0, \lambda_{2}=0$, then the decision-making variables and the Lagrangian factors of the two enterprises are:

$$
\begin{aligned}
& q_{1}^{t s^{*}}=\frac{E}{e} ; q_{2}^{t s^{*}}=\frac{\left(a e-e^{2} t-E b\right) k}{e\left(2 b k-t^{2}\right)} ; e_{2}^{t s^{*}}=\frac{2 b k e^{2}-a e t+E b t}{e\left(2 b k-t^{2}\right)} ; \\
& \lambda_{1}=\frac{k b\left(a e-e^{2} t-3 E b\right)+\left(t e^{2}+2 E b-a e\right) t^{2}}{e^{2}\left(2 b k-t^{2}\right)}
\end{aligned}
$$

4) If $t<\min \left\{\sqrt{2 b k}, \frac{a e-3 E b}{e^{2}}\right\}$, and $k b\left(a e-e^{2} t-3 E b\right)+\left(t e^{2}+2 E b-a e\right) t^{2}>0, \quad$ in this case the profits of the two enterprises can be given by:

$$
\begin{aligned}
\Pi_{1}^{t * *} & =\frac{\left(\left(b e(a+t e)-E b^{2}\right) k-(E b-a e) t^{2}\right) E}{e^{2}\left(2 k b-t^{2}\right)} \\
\Pi_{2}^{t *} & =\frac{\left(e^{4} t^{2}+6 E b e^{2} t-2 a e^{3} t+E^{2} b^{2}-2 E a b e+a^{2} e^{2}\right) k-2 E e^{2} t^{3}}{2 e^{2}\left(2 k b-t^{2}\right)}
\end{aligned}
$$

5) If $\lambda_{1}=\lambda_{2}>0$, then there is no solution.

6) If $\lambda_{1}=0, \lambda_{2}>0$, then there is no solution.

Due to the complexity of profit function and 
constraint conditions, it is impossible to judge the optimal profit of the two enterprises when they use different strategies in the form of analytical form. Next, it will be analyzed in the form of calculating-examples: we assume that the parameters are $e=0.7, b=0.5, k=1$,

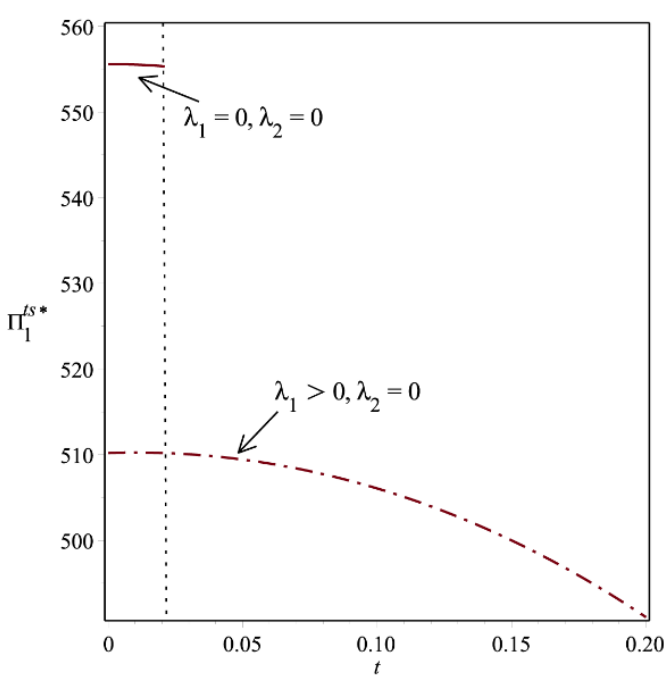

Figure1: The profit of Enterprise 1

From Figure 1 and Figure 2 above, it can be seen that when carbon trading price is low, Enterprise 1 using carbon trading strategy prefers $\lambda_{1}=\lambda_{2}=0$, while Enterprise 2 using low carbon technology prefers $\lambda_{1}>0, \lambda_{2}=0$, and there was no agreement on a production plan between the enterprises. When the price of carbon trading price is high, only $\lambda_{1}>0, \lambda_{2}=0$ is the feasible production plan.

\subsection{All adopt low-carbon technology}

When all adopt the low-carbon technology, the profit function can be written as:

$\Pi_{i}^{s s}=p q_{i}^{s s}-\frac{k\left(e-e_{i}^{s s}\right)^{2}}{2}+t\left(E-e_{i}^{s s} q_{i}^{s s}\right)$

s.t. $E \geq e_{i}^{s s} q_{i}^{s s}$

According to the nonlinear programming and the Nash equilibrium in static games method, the following cases are considered:

1) If $\lambda_{1}=\lambda_{2}=0$, then $q_{1}^{s s *}=q_{2}^{s s *}=\frac{k(a-e t)}{3 b k-t^{2}} ; e_{1}^{s s *}=e_{2}^{s s *}=\frac{3 b e k-a t}{3 b k-t^{2}}$.

2) If $t<\min \left\{\frac{a}{e}, \sqrt{3 b k}, \frac{3 b k e}{a}\right\}$, this solution is the $\mathrm{K}-\mathrm{T}$ point, and the equilibrium profit of

the two enterprises can be written as:
$\Pi_{1}^{s * *}=\Pi_{2}^{s s *}=\frac{2 E t^{2}+k\left(2 b e^{2} t^{2}+k^{2}\left(\left(18 E b^{2}-4 a b e\right) t+2 a^{2} b\right)-k\left(t^{4} e^{2}-t^{3}\left(2 a e q_{112}^{t s} E \overline{E b}\right) \frac{E}{e^{+}} e^{2} q q^{t}\right)\right)}{2\left(3 b k-t^{2}\right)^{2}}=\frac{\left(a e-e^{2} t-E b\right) k}{e\left(2 b k-t^{2}\right)}$ in the range

3) If $\lambda_{1}=\lambda_{2}>0$, then there's no K-T point, $a=50, E=20$ according to the constraint conditions, the profit function of different outputs is drawn under different production strategies of Enterprise 1 and Enterprise 2, as shown in Figure 1 and Figure 2 respectively:

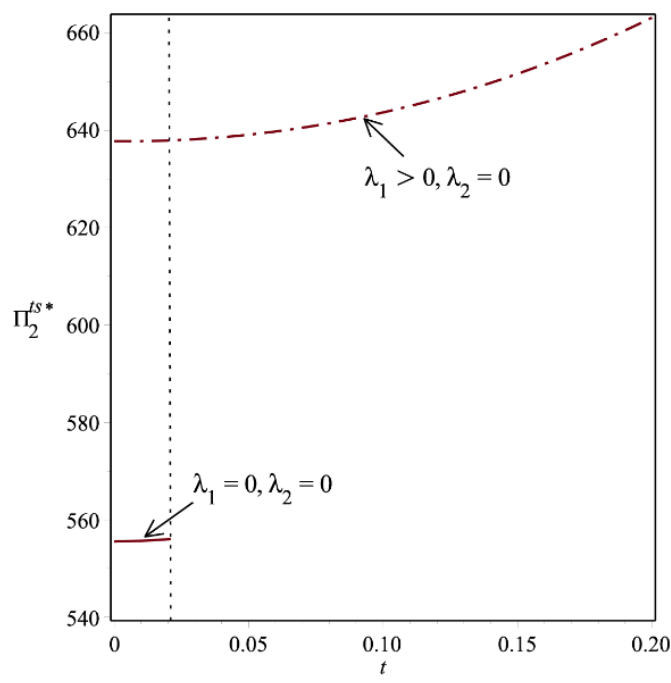

Figure2: The profit of Enterprise no solution.

4) If $\lambda_{1}=0, \lambda_{2}>0$, then there's no K-T point, no solution.

5) If $\lambda_{1}>0, \lambda_{2}=0$, because of the symmetry of two enterprises, there is no solution.

\section{Equilibrium Analysis}

According to the analysis of the fourth case, we can obtain the optimal output and profit of the two enterprises under different production strategies. Due to the complexity of the equilibrium profit function and the constraint conditions, we still use calculating-examples to analyze the equilibrium production strategy of enterprises in competitive environment. We assume that the parameters are $e=0.7, b=0.5, k=1, a=50, E=20$ which are consistent with the above parameters in Section 4.The following cases are discussed respectively:

1) When two enterprises adopt the carbon $0<t \leq 59.18$, the optimal output is $q_{1}^{t * *}=q_{2}^{t * *}=\frac{a-e t}{3 b} ;$

2) When Enterprise 1 adopts the carbon trading strategy while Enterprise 2 adopts the low-carbon strategy, the optimal output is $t \in(0.21,0.4)$;

3) When two enterprises adopt low carbon technology simultaneously, the optimal output is trading strategy and the constraint condition is 
$q_{1}^{s s *}=q_{2}^{s s *}=\frac{k(a-e t)}{3 b k-t^{2}}$ in the range $t \in(0,0.21)$. In the following, under the above constraints, the equilibrium strategy of different production combinations of optimal output is discussed.

Firstly, we assume that the production strategy of Enterprise 2 is unchanged then the choice of production strategy of Enterprise 1 is analyzed. So the equilibrium profit relationship of Enterprise 1 under different production strategies is shown in Figure 3:

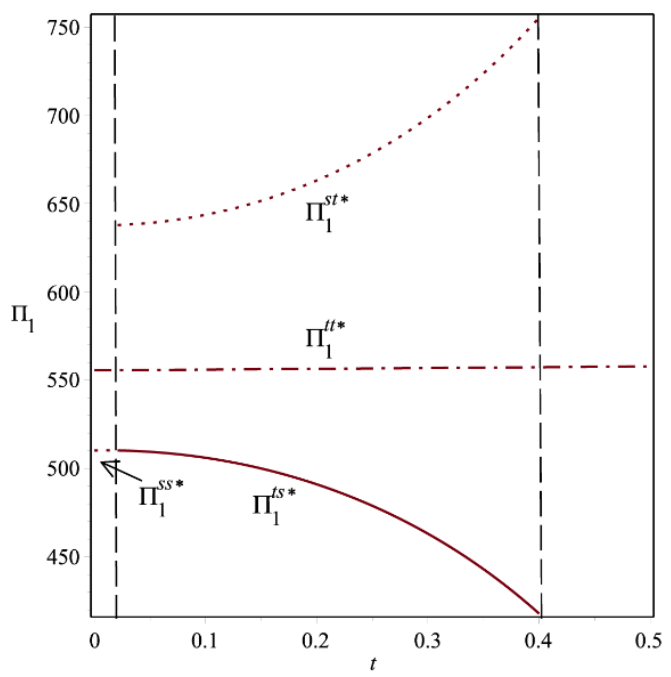

Figure 3 The equilibrium analysis of Enterprise1

As can be seen in Figure 3, when the carbon trading price is very low, two enterprises adopt carbon trading or adopt low-carbon technology simultaneously; with the increase of carbon trading price, $\{s, s\}$ will not be established, while $\{t, t\}$ will be established; when the price of carbon trading is high enough, only $\{t, t\}$ will be established.

As shown in Figure 1, when Enterprise 2adopts the carbon trading strategy, if the price of carbon trading is very low or very high, then Enterprise 1 also adopts the carbon trading strategy; if the price of carbon trading is in the middle, Enterprise 1 adopts low-carbon technology; when Enterprise 2 adopts low-carbon technology, if the carbon trading price is very low, Enterprise 1 also adopts low-carbon technology; if the price of carbon trading is in the middle, carbon trading strategy is adopted; when the price of carbon trading is very high, it doesn't work. Because Enterprise 2 and Enterprise 1 have the symmetry property, it can be used to get the choice of production strategy of Enterprise 2 similar to Enterprise 1.

According to the above analysis, we can get the equilibrium production strategies of two enterprises: when the price of carbon trading is very low, the feasible production strategies of both enterprises are $\{t, t\} ;\{s, s\}$. Figure 3 shows that both enterprises use carbon trading strategy to make profit better than the low carbon technology strategy, so the equilibrium strategy is $\{t, t\}$ in this case; when the price of carbon trading is in the middle, there is no pure strategy Nash equilibrium strategy, because both enterprises prefer to adopt the strategy of differentiating their competitors; when the price of carbon trading is larger, there is only one strategy for the two enterprises to choose, which is to adopt a carbon trading strategy.

\section{Conclusions}

This paper investigated the production strategy of enterprises under the constraint of carbon quota. When the enterprises are constrained by carbon quotas, that is, the total amount of carbon emissions allocated by the government is less than the total amount of the production emissions of the enterprises, the enterprises need to consider the production strategy to meet the production demand. This proposed work proposed models for the optimal choice of enterprise's production strategy under the monopoly environment and the competitive environment respectively, that is, carbon trading or low-carbon technology. This study found that under the monopoly environment, the enterprises choose technological innovation strategy under the condition that the K-T point is established in the constraint range of carbon trading price. Under the competitive environment, when the carbon trading price has a smaller or larger value, the optimal production strategy of two enterprises is the carbon trading strategy, but when the carbon trading price is in the middle, there is no pure strategy Nash equilibrium, because two enterprises have preference to using production strategies different from competitors. Although the method of nonlinear programming is used to study the production strategy of enterprises under the constraint of carbon quota, there are still some problems. Due to the complexity of the variable constraints caused by the equilibrium profit analytic and the nonlinear programming, it cannot fully be proved by mathematical proof in the form of analytic solution. In addition, this paper also can be further studied from the following several 
aspects: technology spillovers under the constraint of carbon quota should be considered, and the government's low carbon subsidies

\section{References}

1. Baranzini A, Goldemberg J, Speck S. A future for carbon taxes[J]. Ecological Economics, 2000, 32(3):395-412.

2. Barari S, Agarwal G, Zhang W J, et al. A decision framework for the analysis of green supply chain contracts: An evolutionary game approach[J]. Expert Systems with Applications, 2012,39(3): 2965-2976.

3. Barker T, Baylis S, Madsen P. AUK Carbon/Energy Tax: The macroeconomics effects [J] . Energy Policy, 1993, 21(3):296 -308 .

4. Blanchet A, Carlier G. Optimal transport and Cournot-Nash equilibria[J]. Mathematics of Operations Research, 2015, 41(1): 125-145.

5. Cao J, Wang J. Absolute exponential stability of recurrent neural networks with Lipschitz-continuous activation functions and time delays.[J]. Neural Networks, 2004, 17(3):379-390.

6. Chaabane A, Ramudhin A, Paquet $M$. Design of sustainable supply chains under the emission trading scheme[J]. International Journal of Production Economics, 2012, 135(1):37-49.

7. Du S, Ma F, Fu Z, et al. Game-theoretic analysis for an emission-dependent supply chain in a 'cap-and-trade'system[J]. Annals of Operations Research, 2015, 228(1): 135-149.

8. Dobos I. Tradable permits and production-inventory strategies of the firm[J]. International Journal of Production Economics, 2007, 108(1-2):329-333.

9. Earl P,Wakeley T. Economic perspectives on the development of complex products for increasingly demanding customers. Research Policy, 2010, 39: 1122-113.

10. Georg Peters, Roger Tagg. Intelligent Concepts for the Management of Information in Workflow Systems[J]. International Journal of Computational Intelligence Systems, 2009, 2(4):332-342.

11. Gong X, Zhou S X. Optimal production planning with emissions trading $[\mathrm{J}]$. Operations Research, 2013, 61(4): 908-924.

12. Guo J D, MaS G. Carbon Emissions reduction strategy for manufacturer-leading influence on the choice of enterprise's production strategy and so on.

supply chain under cap-and-trade scheme [J].Techno-economics \& Management Research,2017(1).

13. Hou Y M, Pan D, Liang C Z. Research on production and emission reduction of two-oligopoly in the trading of carbon emission rights $[\mathrm{J}]$. Commercial Research, 2013, 55 (1): 176-182.

14. $\mathrm{Hu} \mathrm{Z}$, Rao $\mathrm{C}$, Zheng $\mathrm{Y}$, et al. Optimization decision of supplier selection in green procurement under the mode of low carbon economy[J]. International Journal of computational intelligence systems, 2015, 8(3): 407-421.

15. $\mathrm{Hu} \mathrm{Z}$ Y, LiuJ, Liu Y W. General equilibrium analysis of carbon tax under different tax return mechanisms $[\mathrm{J}]$. China soft science, 2011, (9): 55-64

16. $\mathrm{Hu}$ Y Q. Operational research,3rd edition[M]. Tsinghua University Press,2007.

17. Huang S J, Ren Y L, Sun R, et al. Stochastic differential game models of vertical cooperative mitigation in duopoly electricity market [J]. Chinese Journal of Management Science, 2014,22(2):101-111.

18. Jansen M C, Özaltın O Y. Note on Cournot Competition Under Yield Uncertainty[J]. Manufacturing \& Service Operations Management, 2017, 19(2): 305-308.

19. Jian L I, Qin S U, Li M A, et al. The research of carbon trading model on supply chain under carbon emission constraints [J]. Chinese Journal of Management Science, 2016, 24(4):54-62.

20. Jira C F, Toffel M W. Engaging supply chains in climate change $[\mathrm{J}]$. Social Science Electronic Publishing, 2011, 15(4):559-577.

21. Kemfert C, Welsch H. Energy-capital-labor substitution and the economic effects of $\mathrm{CO} 2$, Abatement: Evidence for Germany[J]. Journal of Policy Modeling, 2000, 22(6):641-660.

22. Liu C M, Gao Y. Research on carbon emission reduction in China's industrial sector under carbon trading $[\mathrm{J}]$. Soft science, 2016, 30 (3): 85-88.

23. Liu M W, Wan M Y, Kai-Lan W U, et al. Research on supply chain horizontal cooperation for emission reduction under 
the cap and trade policy [J]. Industrial Engineering \& Management,

24. López-Yáñez I, Argüelles-Cruz A J, Camacho-Nieto O, et al. Pollutants time-series prediction using the Gamma classifier[J]. International Journal of Computational Intelligence Systems, 2011, 4(4): 680-711.

25. Lu L. Supply chain decision and coordination under different carbon emission policies[D]. University of Electronic Science and Technology of China, 2014.

26. Perdan S, Azapagic A. Carbon trading: Current schemes and future developments[J]. Energy policy, 2011, 39(10): 6040-6054.

27. Subramanian R, Gupta S, Talbot B. Compliance strategies under permits for emissions[J]. Production \& Operations Management, 2007, 16(6):763-779.

28. Todd M J. Computation, Multiplicity, and Comparative Statics of Cournot Equilibria in Integers[J]. Mathematics of Operations Research, 2016, 41(3): 1125-1134.

29. Wang Q P, Zhao D Z. Revenue-sharing contract of supply chain based on consumer's preference for low carbon products $[\mathrm{J}]$. Chinese Journal of Management Science, 2014, 22(9):106-113.

30. Wong S. The influence of green product competitiveness on the success of green product innovation. European Journal of Innovation Management, 2012, 15 (4), 468-490 .

31. Xie X, Zhao D Z. Research on cooperation strategy of enterprises' carbon emission reduction in low carbon supply chain[J]. Journal of Management Science, 2013, 26(3): 108-119.

32. Xie Y, Yi S, Tang Z, et al. Uncertainty multi-source information fusion for intelligent flood risk analysis based on random set theory[J]. International Journal of Computational Intelligence Systems, 2012, 5(5): 975-984.

33. Xie Z Y. Economic game theory[M]. Fudan University Press, 2002.

34. Yu D, An S, Hu Q. Fuzzy mutual information based min-redundancy and max-relevance heterogeneous feature selection[J]. International Journal of Computational Intelligence Systems, 2011, 4(4): 619-633.

35. Zhu Y B,Liu X,WangZ. Abatement effect of carbon tax and its impacts on economy in 